\title{
The model of sustainable management of building energy performance characteristics
}

\author{
Rūta Mikučionienè, Vytautas Martinaitis \\ Vilnius Gediminas Technical University, Saulètekio al. 11, Vilnius 10223, Lithuania
}

\begin{abstract}
The straight way to perform the targets of the Energy Efficiency Directive is the renovation of the existing buildings. Qualitative renovation begins by professional analysis of actual energy consumption and by choosing the packet of energy efficiency measures. The methodology for continual improvement and handy decision making can help to enhance the renovation process. This paper presents the concept of the model of sustainable management of building energy performance characteristics. The model is the algorithm for continual process for evaluation of current building construction operating and maintenance information, evaluation and prioritization of energy efficiency measures, the formation of their packets for suggestions for decision maker or for building administrator. In the presented model the five main criteria (energy efficiency, environmental impact, economical rationality, comfort and duration under Life cycle point of view) are used as criteria reflecting sustainable attitude. Sequential prioritization and distribution decision tree is constructed for distribution of energy efficiency measures to the basic and additional energy efficiency measures. The case study illustrates the optimization of packets formation, and represents the systemized information output for decision maker or building administrator.
\end{abstract}

Keywords: energy efficiency in building; sustainability continual improvement; decision making; criteria.

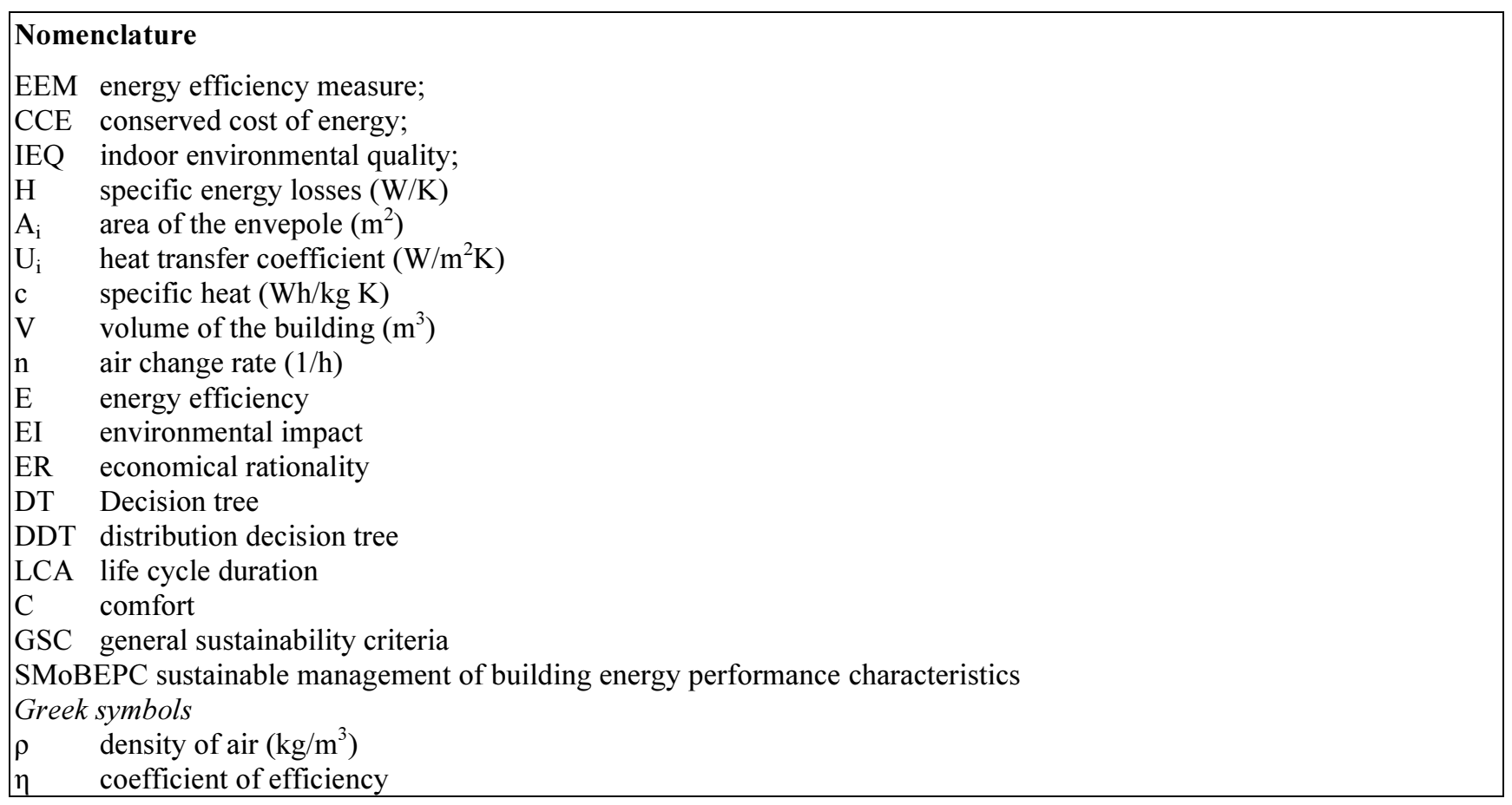

Corresponding author: Rūta Mikučionienė. E-mail address: ruta.mikucioniene@vgtu.lt

http://dx.doi.org/10.3846/enviro.2014.272

(C) 2014 The Authors. Published by VGTU Press. This is an open-access article distributed under the terms of the Creative Commons Attribution License, which permits unrestricted use, distribution, and reproduction in any medium, provided the original author and source are credited. 


\begin{tabular}{|ll}
\hline Subscripts \\
del & delivered. \\
$\mathrm{R}, \mathrm{k}$ & heat revocery \\
$\mathrm{L}$ & losses \\
$\mathrm{SUN}$ & solar radiation. \\
$\mathrm{E}$ & electrical appliances \\
$\mathrm{P}$ & people. \\
$\mathrm{T}$ & internal temperature \\
$\mathrm{I}$ & internal \\
\hline
\end{tabular}

\section{Continual assessment and improvement from economical to sustainable point of view}

The one of major energy consumers in the world is buildings sector [1], but rate of new buildings construction in Europe is about $1 \%$ and rate of renovation is only about $1-2 \%$ per year according different sources [2]. The newest Energy Efficiency Directive [3] is reflected to the fact that global energy savings will be achieved when majority of the buildings will be energy efficient. So the renovation of the existing buildings is straight way to this aim. For logical and useful renovation the qualitative analysis of initial situation of the building is required as well as the decision for energy efficiency measures. Analysis of energy consumption in operation and maintenance exploitation stage is very important [4], the continuous assessment should be the base for detailed energy audits. One time decision making is not the challenge in the modern-day science as well. Continually updating tool for decision making is new trend for the scientists and innovative practicians.

An innovative intelligent decision support model for the identification of the need for intervention and the evaluation of energy-saving measures in a typical existing building [5] is one of examples for continuous assessment. The principle of this model is the comparison of specific building indexes (based on the examined building's operations from BEMS data) with its standard values. Model indicates the status of the building for the chronic period that the data are used and consequently the need for retrofit measures. The output is financial evaluation of the proposed energy efficiency measures as support for decision maker. The proposal database in this model is collected through thorough survey of the energy-efficiency measures implemented for existing buildings in Greece in the past years.

The study for sustainability assessment for renovation packages [6] focuses not only on economic benefit. It is stated that targeting only energy savings in formation of EEM packages can affect IEQ negatively. The presented methodology assesses economic, indoor environment quality and specific environment aspects for evaluation of EEM packages.

The Deming cycle usually used in the business management is created for management of continual processes and improvements. the scientists $[7,8]$ started using this cycle and „open“ it for implementation of innovations and renovation measures. The study performed by [7] present the multicriteria evaluation for EEM based on criteria tree formation to evaluate the optimal renovation actions in multicriteria „knapsack“ model, which has sequential repeating for decision making. But algorithm stops then decision is done. This method does not have continuity. Serbian scientists [8] presents method for optimization of industry processes, which is based on Deming cycle. The goal for decision maker is described by free parameters: quality, productivity and flexibility.

Scientists of electronics and automation usually tackle the problem of continual supervision of energy consumption. Their studies usually examines reliability of the sensors and controllers [9], the elimination of errors [10], data processing and storage problems [11]. The energy efficiency in these studies is understood as maximally smoothly working energy systems. In the study [12] the goal is to optimize for building elements (construction, systems, services and management) and correlation of them.

The review of methods of buildings energy performance assessment and continual improvement open three parts for analysis for construction of model for sustainable management of building energy performance characteristics. The first step is analysis of initial data - consumption analysis.

[13-15] and others state, that the most accurate analysis of energy consumption is analysis based on actual consumption, but simulated detecting the differences, and eliminating the detected reasons. The factors influencing energy consumption should be known to detect the differences. Factors influencing the energy consumption in the building can be divided in to 4 groups: climate (outdoor temperature, solar irradiation and wind speed), thermal characteristics of building, occupant's behavior (the use of electrical appliances is the result of occupant's behavior as well) and building services system and operation. The main reason, which influence the difference of the results for energy consumption, researchers [13-15] refer to occupants behavior.

Heat balance method and weighting-factor method are two basic methods to resolve the heating load or energy consumption [16]. The basis of weighting factor method also called heat transfer method is evaluation of heat losses through the envelope of the building and attribution of weight coefficients for them. The heat balance method is more accurate, because the heat gains and heat fluxes from different energy systems inside the building can be evaluated. For this reason the new generation simulation programs for buildings energy use are based on heat balance method [16].

When energy consumption analysis is done, the next step for qualitative renovation is to choose energy efficiency measures (EEM). But to choose EEM - to make decision which alternative is the best - the criteria should be defined first. Criteria should be defined for all kinds of decision making methods.

The evaluation and prioritization of EEM depends on the chosen criteria. The most commonly used criterion is economical evaluation [5, 17-19]. Another popular criteria for evaluation of EEM is energy efficiency or energy saving. It 
is related with economic criteria, because without saving will be no financial benefit of implementation of EEM. So the measure which is economically feasible has energy savings as well. As described in [20] the measures are evaluated by energy savings. The energy efficiency criteria often is used together with criteria of environmental impact and in literature is presented as 2E criteria [21] and with economic criteria 3E evaluation [22]. Environmental and energy efficiency criteria usually are met Life cycle analysis (LCA) $[23,24]$. But LCA usually is performed for separate building elements, or not for impact of whole building [25]. The LCA evaluation together with energy efficiency lets to analyze the EEM in two-fold benefit, related to energy savings and improvement of buildings element conditions [18]. The environmental impact is expressed by the potential of reduction of $\mathrm{CO}_{2}$ emissions [7].

The state-of -the art and sustainable evaluation of EEM usually is performed using not only one criterion, but composing several ones. The selection of criteria depends on the aim of analysis.

The multi criteria evaluation of sustainable EEM performed by [26] use four criteria: use of energy, thermal comfort, cost and environmental impact. This combination of criteria comparing with others is sustainable, but is focused more on usage of the building, and not in life cycle aspects. Sustainable office building renovation presented by [27] has five criteria: sustainable site - evaluating current situation of building, energy efficiency, water efficiency, material and resources evaluation renewability and waste management and indoor environment quality.

All described criteria can be divided into quantitative and qualitative criteria. The quantitative criteria (investment cost, energy savings and etc) are indicators which can be calculated and evaluated objectively. The qualitative (aesthetics, comfort and etc) are subjective and evaluation of them depend on decision maker. But sustainable evaluation of renovation should be evaluated according both quantitative and qualitative factors [28].

Summarizing the described studies with different purposes of EEM evaluation and different criteria, the conclusion is that to evaluate EEM is sustainable and universal aspect should be used the complex of criteria, which involve energy efficiency, environmental impact, economical rationality, comfort and life cycle duration.

When criteria are defined the clear structure and procedure for decision making should be defined. It is easier to implement energy efficiency measures to newly designed and constructed buildings than to old ones (already built ones). To assess their situation and adapt energy efficiency measures there is a need of deep knowledge and expertise of various specialists. This raises the need for this expertise to organize, generate the optimal, best individually suited kits of building energy efficiency measures. Multi criteria decision making-separate area of science and its application in choosing correct building EEM requires interdisciplinary approach. Decision tree (DT) is a versatile information clustering and classification tool used in a wide range of scientific and industrial fields.

The use of DT for researches in the building sector is rare today [29]. Most commonly this method is used for optimization of construction processes [17, 30]. The Japanese scientists applied DT method for rating of the building according the energy demand. The building energy demand predictive model based on DT method was created, based on analysis of existing buildings. The another study performed by [7], use DT method for criteria tree formation to evaluate the optimal renovation actions in multicriteria „,knapsack“ model, which has sequential repeating for decision making.

Summarizing the described studies with different purposes of EEM evaluation and different criteria, the conclusion is that to evaluate EEM in sustainable and universal aspect the complex of criteria should be used, which involve energy efficiency, environmental impact, economical rationality, comfort and life cycle duration. It is more appropriate and clear to perform the sequential and cyclical decision making by decision tree method. The model of sustainable management of building energy performance characteristics was created, which is based on energy consumption analysis by heat balance equation and DT method for decision making by five sustainability criteria.

\section{Methods}

The construction of model for sustainable management of building energy performance characteristics needs to find answers into three questions: method for energy consumption analysis, criteria for EEM evaluation and method for decision making.

\subsection{Equation for energy consumption analysis}

The new heat balance is comprised in the way to utilize the maximum heat gains providing building services with comfort conditions. Another one requirement for heat balance is appropriate number of members in equation, for convenient evaluation of energy saving measures. When heat balance is used for continual assessment the specific consumption (expressed in $\mathrm{W} / \mathrm{K}$ ) is more appropriate, because the indoor and outdoor climate information would be eliminated and only "pure" consumption analyzed. The energy generation is not considered, because the boundary of equation is only the building space. So the member of renewable sources is eliminated as well. Heat gains are separated by its origins as in [31], for optimal usage of each heat gains.

As mentioned earlier for deep analysis of energy consumption the load profile is more convenient. For this purpose the energy (resources) heat balance equation is constructed from specific energy consumption. To get the specific heat balance, both sides of the energy consumption balance are divided by degree hours.

The target of the analysis of energy consumption and implementation of energy saving measures is comfort conditions in the building. So the equation is rewritten by "bottom up" method, starting from final consumer [32] to ensure comfort 
conditions in the building. In the left side of balance equation equality is heat, which is needed to ensure comfort conditions $\left(\sum A_{i} u_{i}+c \rho \sum V_{j} n_{j}\right)$. And in the right side of equality the delivered heat is presented:

$$
\sum A_{i} u_{i}+c \rho \sum V_{j} n_{j}=\sum H_{d e l}+\eta_{T}\left(H_{P}+\eta_{E} H_{E}+H_{S U N}\right)+\sum \eta_{R, k} H_{R, k}-\sum H_{L, k}
$$

where $H_{d e l}$ - specific resources consumption, $\mathrm{W} / \mathrm{K} ;\left(\sum A_{i} u_{i}+c \rho \sum V_{j} n_{j}\right)$ - specific heat losses $\mathrm{W} / \mathrm{K} ; \eta_{T}$-gains utilization factor according internal temperature; $H_{P}$-internal gains from inhabitants, $\mathrm{W} / \mathrm{K} ; \eta_{\mathrm{E}}-$ utilization factor for gains from electric appliances; $H_{E}-$ internal gains from electric appliances, $\mathrm{W} / \mathrm{K} ; H_{S U N}-$ gains from solar radiation, $\mathrm{W} / \mathrm{K} ; \eta_{R, k}-$ heat recovery efficiency factor; $H_{R, k}$ - specific recovered heat from ventilation and domestic hot water systems, $\mathrm{W} / \mathrm{K} ; H_{L-}$ heat losses from building services systems, $\mathrm{W} / \mathrm{K}$.

The flow of delivered resources has two streams of energy (electricity and heat) and water. The electricity flow has two ways: one is electricity consumed by lighting, electrical and auxiliary appliances. The balance is based on heat flow, so in concept of heat, the energy (electricity) used but the heat which is not extracted is loss $\left(\mathrm{H}_{\mathrm{L}}\right)$ in point of heat flow. The amount of energy from electrical appliances transformed to heat is heat gained from electrical appliances $\left(H_{E}\right)$.

The described heat balance equation for distribution of heat according its origin lets to analyze and find the main points, where heat is consumed. This way of analysis is very visual how the utilization of gains and heat recovery possibilities can be used for more efficient energy use. Also this equation is applicable to energy analysis for continual improvement and is very handy when changes only part of energy consumption, and recalculations become easier, then only data about alternation needs to be recalculated.

\subsection{Criteria tree of general sustainability criteria}

Qualitative renovation begins by choosing energy efficiency measures (EEM). But to choose EEM - to make decision which alternative is the best - the criteria should be defined first. In order to increase sustainability of the renovation the criteria for EEM evaluation reflecting sustainable attitude should be chosen.

One of the main sustainability criteria is energy efficiency (EE). The expression of EE usually is described as saved energy. The energy saving is understandable as energy use for ensuring qualitative energy services using less energy or reducing the energy services when circumstances are beneficial for it. Saved energy is calculated as difference of annual energy consumption (recalculated to normal year) before and after renovation. The saved energy can be in different form (electricity or heat), so to evaluate it universally recalculation to the primary energy should be done. The primary energy saving is more comprehensive attribute of EE criteria. Another attribute characterizing EE is change of heat load. This attribute prioritize the complex renovation and selection of several EEM at the same time. For example the retrofit of building envelope will not make changes in the load of heat substation if the renovation of heat substation is not performed. Two attributes of EE for sustainable EEM evaluation are defined, to characterize the saved primary energy and to prioritize the complexity in renovation process.

Environmental impact (EI) is one of the main criteria in sustainable evaluation. The renovation process impacts environment in two lines. One line is reduction of pollution by reduction of energy use. Another line is emitted pollutants during the renovation process and manufacturing and transporting the materials for renovation. The EI criteria can be evaluated by two attributes (saved pollution and emitted pollution by renovation process), or can be expressed by the ratio of these indicators. The usage of the described ratio as only one attribute of EI criteria simplify the calculation process for decision making and is more appropriate to use.

Economical rationality (ER) criterion also has to be assed in sustainable development. The attributes where selected to show the general view of renovation benefit in economical point of view. NPV was defined to show the time value of money, because it is more informative (comparing with IRR) when cash flows are not equal and represents the situation better when reinvestments to EEM are needed. The real payback period reflects depreciation of money in time, so it is more accurate comparing with simple payback period when payback is longer than one year. For planning renovation the initial investment is important. The initial investment attribute lets to sort EEM measures to groups of small and big investment needful EEM. The renovation profit expressed by cost of conserved energy (CCE) compare the implementation of EEM with doing nothing. If CCE of EEM is bigger than price of energy it shows, that is not rational to implement EEM, it is cheaper to consume energy [33]. CCE is calculated as ratio of investment and savings for lifetime of measure considering the discount rate for that period. To define the increased value of the building by implementing the EEM, the rehabilitation of building element should be evaluated. Coefficient of buildings element rehabilitation depends on life time of building element and the actual age of building element [18]. Multiplying the coefficient of buildings element rehabilitation by investment cost the increase of building element value is presented. This attribute lets to prioritize the EEM with big investment cost, but which are obligatory for rehabilitation building element [21]. Concluding the review of economical rationality attributes to evaluate economic benefit not only the real payback period, NPV and initial investment has to be evaluated but CCE and increase in the value of building has to be defined as well.

The limits of requirements for physical comfort usually are described in standards. Evaluating the impact of EEM it can be defined in binary question for decision maker: meet requirement (evaluation - 1) do not meet requirements (evaluation 0 ). The personal part of comfort can be evaluated only by survey with inhabitants. The comfort criterion lets to evaluate benefit for building, where indoor environment quality hasn't satisfied the normative parameters before modernization. The 
comfort conditions in the building doesn't save energy, but guarantee the functionality of the building, gives benefit for human satisfaction, so for more productive activities.

Life cycle duration of building indirectly is evaluated in EI and ER criteria evaluating by ratio of saved pollution and emitted pollution by renovation process and evaluating coefficient of building rehabilitation and increase of building value. Sustainable supervision of the buildings is actual question of today, the recommended periodicity of renovation (20 years period) by [21] is taken into account. The extension of the building is evaluated by the impact of EEM implementation for whole building and its life cycle duration.

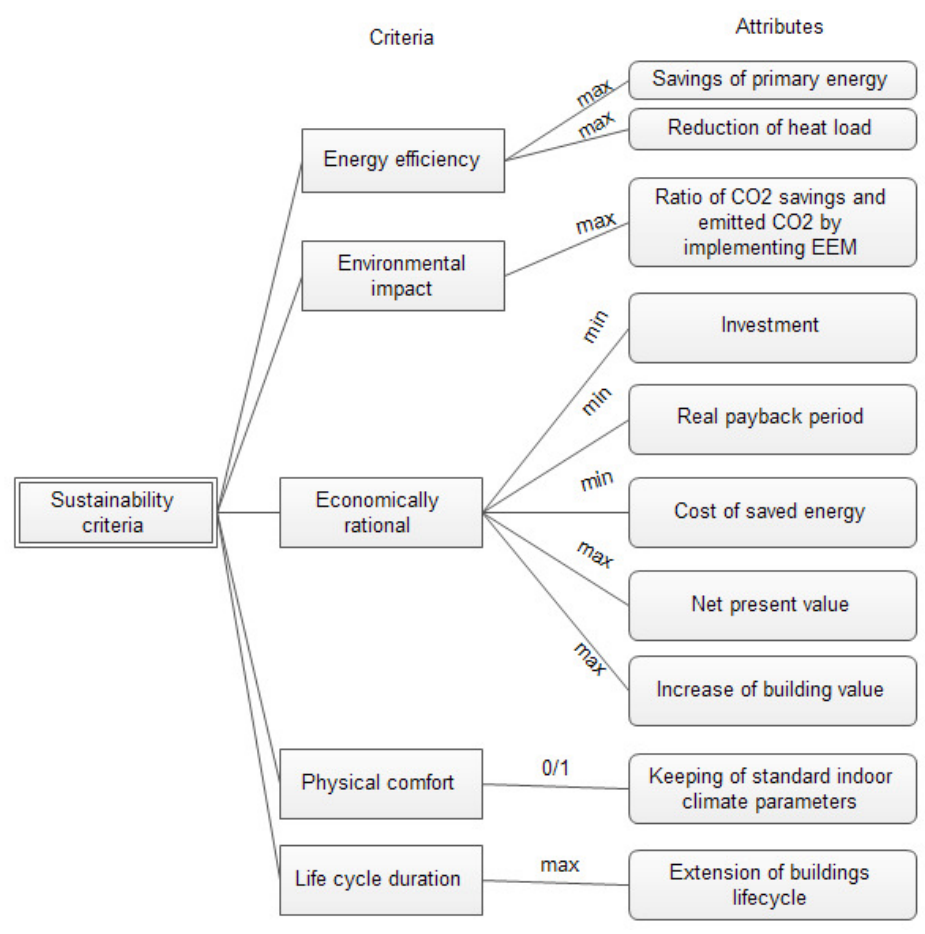

Fig. 1. Tree of sustainability criteria

Sustainable evaluation of EEM can be performed only estimating multicriteria. And multicriteria should cover and be integrated from different fields of science: energy, environment, economy, comfort and construction. The criteria tree with attributes and their optimization functions construct the general sustainability criteria, as it is shown in Figure 1. The general sustainability criteria (GSC) tree consists of 5 criteria, which are expressed by attributes. All attributes have their optimization function, as it is shown in Figure 1.

The selection of criteria and assessment of their attributes is incomplete information for decision maker. Each attribute of the criteria has different units, different optimization functions. The structure for evaluation of attribute values and criteria should be created. Usually the SAW (simple additive weighting) normalization method is used to unify the values [34]. The normalization process is based by comparing attribute values of analyzed alternatives with the best result, and evaluation the difference from the best value.

The weight of each criterion is question for decision maker. The weight can be defined proportionally (equal for each criteria) or different weights can be provided for criteria. Weighting of criteria depends on the expected result by decision maker [7], is useful for prioritization of special criteria and standards limitations. The principle of sustainability is complex view, so according this concept all criteria in described criteria tree are set equally important [35].

\subsection{DT for EEM evaluation}

Then separate EEM are evaluated, the next question for decision maker is how to form the packets of EEM. One way is to form all possible combinations of EEM and then evaluate it. For example if there are 5 EEM 31 combinations should be evaluated (if 10 EEM 1023 combinations will be formed). The optimization of formation of combinations can solve this problem. Sequential prioritization and distribution DT (DDT) is formed for distribution of EEM to the basic and additional EEM's. This method optimizes the formation of EEM packets.

The optimization sequence starts with finding the obligatory EEM, which should be implemented. The obligatory measures have to be defined by decision maker in the first stage, when building is analyzed. The obligatory measures are defined to accomplish the technological or comfort requirements of the building. Also obligatory measures can appear after modernization, and then characteristics of building are changed. All EEM should meet comfort criteria, so the EEM with comfort criteria should be met for all measures, otherwise is eliminated. The evaluation of EEM by general sustainability criteria (GSC) shows which EEM is the best, so it should be added in all packets. Second priority of the EEM is the best 
result of one of criterions (e.g. Energy saving, o economical rational), except comfort criterion. The comfort criterion is evaluated separately in second node of the tree, so is eliminated in the fourth node. The concept of decision tree for EEM distribution to the basic and additional list is presented in the Figure 2.

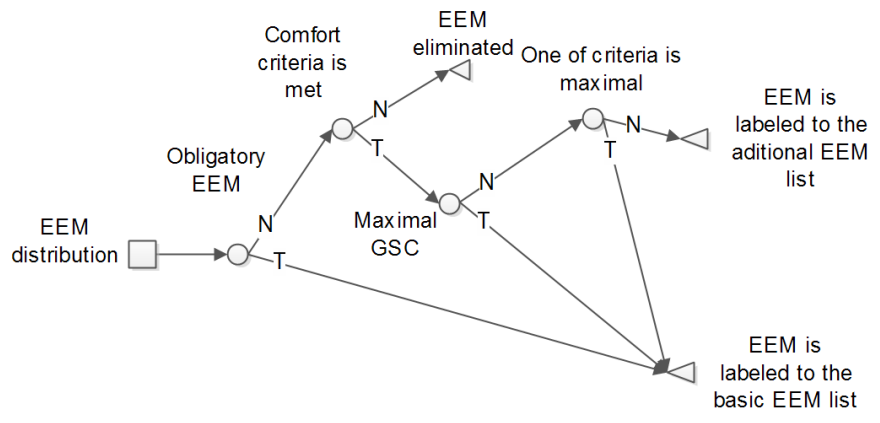

Fig. 2. The principle of distribution decision tree

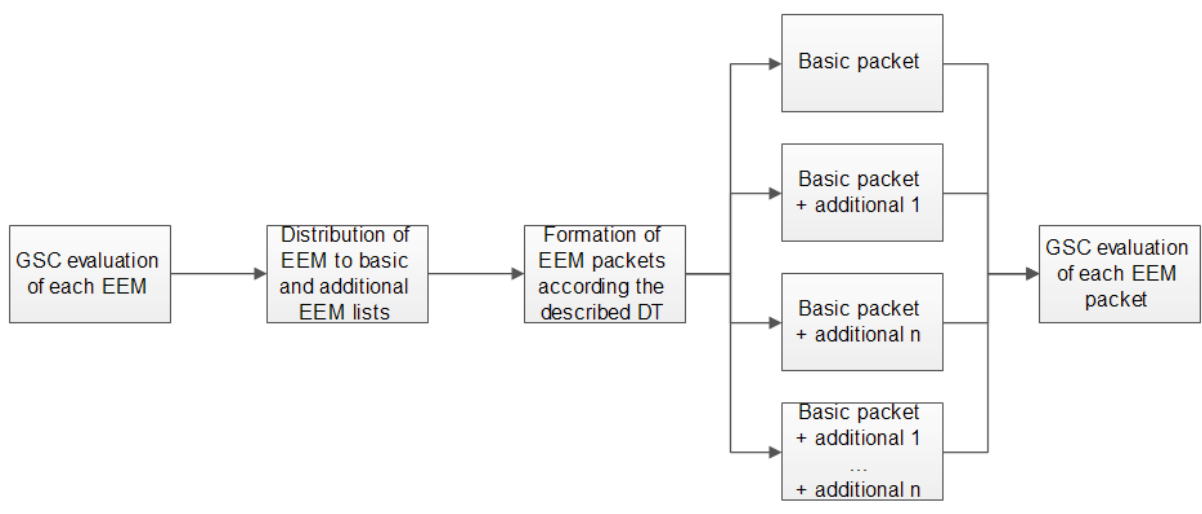

Fig. 3. The sequence of EEM packet formation

The sequence of formation of EEM packet is shown in Figure 3. The principle of this distribution is to evaluate the basic EEM which are obligatory or has very good characteristics in sustainability point of view. These characteristics are described by the maximal GSC. The EEM with the best values of one criterion from five criteria which form the GSC also are labelled to the basic list. All EEM which are not eliminated and do not pass to the basic list form additional list. The EEM from additional list have been added to the basic list randomly in all possible combinations: each EEM separately, two, etc. and finally the packet with all EEM.

The formation of basic list lets to optimize the number of alternative packets and to optimize the decision making to find the best packet of EEM. So with 5 EEM only four packets can be formed instead of 31 if all packets are formed randomly from all EEMs. 10 EEM can form more than 1000 combinations, but distribution decision tree will optimize this number to 20 packets.

\section{The algorithm of sustainable management of building energy performance characteristics}

The sustainable management of building energy performance characteristics (SMoBEPC) is designed for public buildings. The purpose of the model is energy efficient building is sustainable point of view. It means that tightening of the building and "tightening" of energy bills should not pass the requirements for comfort.

In the first part of model algorithm the input about initial data is set and analyzed. The information about building characteristics is building architecture and construction and energy consumption (with the analogical climatic conditions). The architecture and construction are unvaried information except reconstructions cases. The energy consumption (heat and electricity) is varying every day, but has more or less cyclical period of one year.

Then initial building data is set, the actual energy consumption is recalculated to specific energy consumption and heat balance equation (described in paragraph 2.1) is formed. Then EEM are evaluated by GSC as described in paragraph 2.2. Then separate EEM are evaluated, the packages of EEM are formed according distribution decision tree described in paragraph 2.3.

The sequence of described sets is shown in Figure 4, where the algorithm of sustainable management of building energy performance characteristics is presented. The red line shows the continuity of the process, there is no end in the algorithm, it is repeated periodically. 


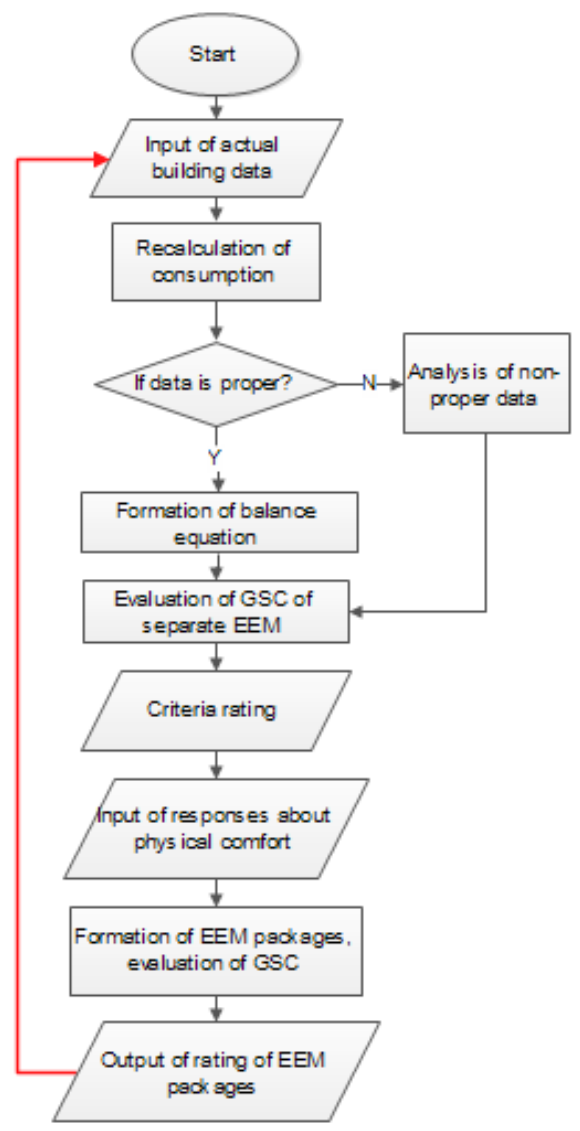

Fig. 4. The algorithm of SMoBEPC

The SMoBEPC is computer assisted process for evaluation of energy consumption and it can evaluate opinion of each person in the building about comfort. Feedback of building occupants about physical comfort has to be analyzed to separate the individual (personal) features, neutral comfort conditions and expected pleasant comfort conditions. The target of comfort conditions feedback system is to define the neutral comfort conditions and to seek for pleasant comfort conditions. The pleasant comfort conditions are not in the first target because pleasant conditions for different occupants (of different age, sex, metabolic rate and etc.) are different, but it can be as the secondary target.

The sustainable management of building energy performance characteristics (SMoBEPC) is continual process which covers energy management system, monitoring and continual decision making tool. The last part of the algorithm is output of rated packages of EEM. This information is specialized for building administrators and managers as decision support tool for more energy efficient building use in sustainability point of view.

\section{Case study of two buildings}

The aim of case study is to show usage of the described model for the real buildings. The examination of model is prepared for two different public buildings. The heat for both buildings is delivered by district heating network. The information about the characteristics of buildings is presented in Table 1.

Table 1. The characteristics of analyzed buildings

\begin{tabular}{lll}
\hline Characteristics & Building 1 (B1) & Building 2 (B2) \\
\hline City & Birštonas & Vilnius \\
Years of construction & 1986 & 2004 \\
Heated area, $\mathrm{m}^{2}$ & 1185,93 & 7194,36 \\
Number of floors & 2 & 12 \\
Heat consumption, $\mathrm{kWh} / \mathrm{m}^{2}$ & 161,91 & 93,62 \\
Ventilation type & Natural & Mechanical with recuperation (efficiency - 50\%) \\
Heat transfer coefficient of external walls, W/m $\mathrm{m}^{2} \mathrm{~K}$ & 1,23 & 0,49 \\
Heat transfer coefficient of roof, $\mathrm{W} / \mathrm{m}^{2} \mathrm{~K}$ & 0,72 & 1,19 \\
Heat transfer coefficient of windows, $\mathrm{W} / \mathrm{m}^{2} \mathrm{~K}$ & 1,7 & 1,262 \\
\hline
\end{tabular}


According to the sequence presented in Figure 2 separate EEMs there evaluated for both buildings. The lists of EEMs were different because of specifics of the buildings. But results of EEM rating and basic packages formation are very similar. Heat substation renovation and insulation of external walls are included in basic package in both cases. Only one difference is in B1, that mechanical ventilation is included in basic packet as obligatory measure. B2 has no obligatory measures. In Figure 5 the sustainability criteria of separate EEM of each building are presented. The insulation of external walls is EEM1 in both cases. The renovation of heat substation is EEM3 in B1 and EEM6 in B2.

Formation of packages show the same tendency in both cases, the bigger packages has better GSC values, then smaller. The Figure 6 presents comparison of best packages of both buildings.

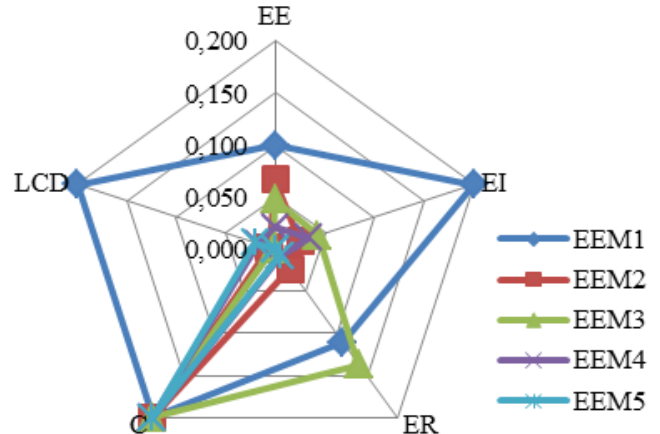

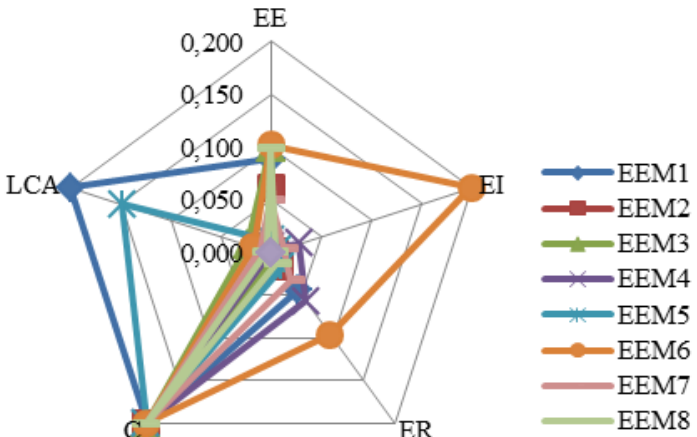

b)

Fig. 5. Sustainability criteria of separate EEM of building 1 (a) and building 2 (b)

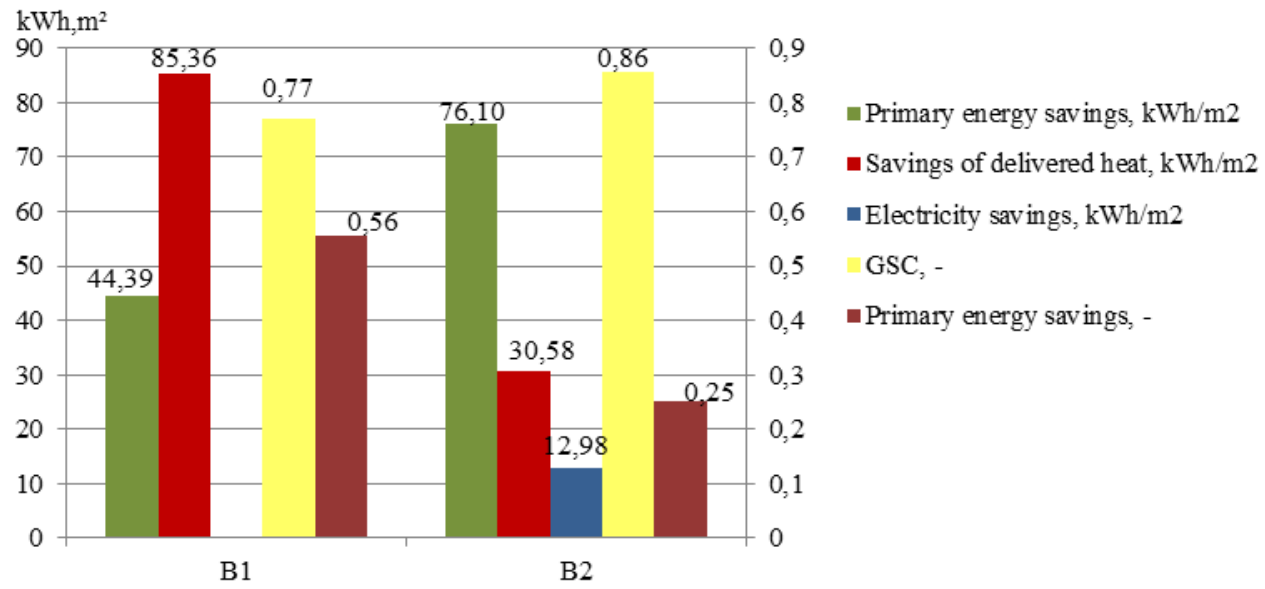

Fig. 6. The comparison of values of two buildings best packages

GSC of both cases is similar $(0,77$ and 0,86$)$, but energy saving indicators are different. Primary energy savings in the parts of units in case B1 is 0,56 , and in case B2 is only 0,25 . One reason of differences is that in case B1, only heat consumption was taken into account, when in case B2 heat and electricity was considered. The second difference is the indicators of district heating network. Case B1 is in city of Birštonas, where main fuel of district heating is wood (80 \%) and factors of primary energy is very low $(0,52)$ comparing with average of Lithuania and Vilnius case $(1,3)$. Savings of delivered heat in case B1 are higher more than twice, because B1 building is older and initial thermal characteristics of building are lower. Savings of delivered heat are different as well, because in case B2 initial consumption of heat is smaller, because building is built later and is tighter.

The example of two different cases shows, that evaluation of GSC express not only the economic benefit, but benefit for human's welfare and for environment as well - the sustainable and complex view to the building.

\section{Conclusions}

Expediently structured specific heat balance equation is applicable to energy analysis for continual improvement and is very handy when changes only part of energy consumption, and recalculations become easier, then only data about alternations needs to be recalculated.

The decision tree method is appropriate for the clear and understandable structure for continuous decision making and evaluation of energy efficiency measures in order to promote the process of existing buildings renovation, to increase their operating and maintenance sustainability. . 
The defined complex of 5 criteria (energy efficiency, environmental impact, economical rationality, comfort and duration in life cycle point of view) covers main fields of sustainable development concept and prioritizes the measures, which are not economically rational, but are obligatory for human's health, or wellbeing and for environmental point of view. The energy efficiency measures evaluation performed with this complex of criteria express sustainable, more general functional approach to buildings.

Proposed limited number of criteria for multicriteria analysis is characterized by clear structure, sequence as easily assessed reliability of received indicators. It enables to define the criteria values according the calculations of defined attributes. Sequential prioritization and distribution is formed under Generalization decision tree to optimize the number of EEM packages.

The example of two different public buildings shows, that evaluation of GSC express not only the economic benefit, but sustainable and complex point of view to the building renovation including the benefit for human's welfare and for environment as well.

\section{References}

[1] European Commission, 2010, Energy -efficient Buildings PPP roadmap and longer term strategy, Publications Office of the European Union, Luxemburg.

[2] the Buildings Performance Institute Europe, 2011, Europe's buildings under the microscope, Buildings Performance Institute Europe, Brussels.

[3] The European Parliament and the Council, 2012, "Directive 2012/27/EU of the European Parliament and of the Council," (October):. 1-56.

[4] Escrivá-Escrivá, G.; Santamaria-Orts, O.; Mugarra-Llopis, F. 2012. Continuous assessment of energy efficiency in commercial buildings using energy rating factors, Energy and Buildings 49:78-84. http://dx.doi.org/10.1016/j.enbuild.2012.01.020

[5] Doukas, H.; Nychtis, C.; Psarras, J. 2009. Assessing energy-saving measures in buildings through an intelligent decision support model, Building and Environment 44(2): 290-298. http://dx.doi.org/10.1016/j.buildenv.2008.03.006

[6] Brown, N. W. O.; Malmqvist, T.; Bai, W.; Molinari, M. 2013. Sustainability Assessment of Renovation Packages for Increased Energy Efficiency for Multi-family Buildings in Sweden, Building and Environment 61: 140-148. http://dx.doi.org/10.1016/j.buildenv.2012.11.019

[7] Alanne, K. 2004. Selection of renovation actions using multi-criteria 'knapsack' model, Automation in Construction 13(3): 377-391. http://dx.doi.org/10.1016/j.autcon.2003.12.004

[8] Arsovski, Z.;Pavlovic, A.; Arsovski, S.; Mirovic, Z. 2009. Improving the Quality of Maintenance Processes by Using Information Technology, Strojniški vestnik - Journal of Mechanical Engineering 55(11): 701-714.

[9] Marinakis, V.; Doukas, H.;Karakosta C.; Psarras, J. 2012. An integrated system for buildings' energy-efficient automation: Application in the tertiary sector, Applied Energy.

[10] Costa, A.; Keane, M. M.; Torrens, J. I.; Corry, E. 2011. Building operation and energy performance: Monitoring, analysis and optimisation toolkit, Applied Energy 101: 310-316. http://dx.doi.org/10.1016/j.apenergy.2011.10.037

[11] Ahmed, A.; Ploennigs, J.; Menzel, K.; Cahill, B. 2010. Multi-dimensional building performance data management for continuous commissioning, Advanced Engineering Informatics 24(4): 466-475. http://dx.doi.org/10.1016/j.aei.2010.06.007

[12] Ahmed, A.; Korres, N. E.; Ploennigs, J.; Elhadi, H.; Menzel, K. 2011. Mining building performance data for energy-efficient operation, Advanced Engineering Informatics 25(2): 341-354. http://dx.doi.org/10.1016/j.aei.2010.10.002

[13] Hernandez, P.; Burke, K.; Lewis, J. O. 2008. Development of energy performance benchmarks and building energy ratings for non-domestic buildings: An example for Irish primary schools, Energy and Buildings 40(3): 249-254. http://dx.doi.org/10.1016/j.enbuild.2007.02.020

[14] Pérez-Lombard, L.; Ortiz, J.; González, R.; Maestre, I. R. 2009. A review of benchmarking, rating and labelling concepts within the framework of building energy certification schemes, Energy and Buildings 41(3): 272-278. http://dx.doi.org/10.1016/j.enbuild.2008.10.004

[15] Fokaides, P. A.; Maxoulis, C. N.; Panayiotou G. P.; Neophytou, M. K. -A.; Kalogirou, S. A. 2011. Comparison between measured and calculated energy performance for dwellings in a summer dominant environment, Energy and Buildings 43(11): 3099-3105. http://dx.doi.org/10.1016/j.enbuild.2011.08.005

[16] Wang, S.; Yan, C.; Xiao, F. 2012. Quantitative energy performance assessment methods for existing buildings, Energy and Buildings.

[17] Verbruggen, A.; Marchohi, M. Al.; Janssens, B. 2011. The anatomy of investing in energy efficient buildings, Energy and Buildings 43(4): 905-914. http://dx.doi.org/10.1016/j.enbuild.2010.12.011

[18] Martinaitis, V.; Rogoža, A.; Bikmaniene, I. 2004. Criterion to evaluate the 'twofold benefit' of the renovation of buildings and their elements, Energy and Buildings 36(1): 3-8. http://dx.doi.org/10.1016/S0378-7788(03)00054-9

[19] Nikolaidis, Y.; Pilavachi, P. A.; Chletsis, A. 2009. Economic evaluation of energy saving measures in a common type of Greek building, Applied Energy 86(12): 250-259. http://dx. doi.org/10.1016/j. apenergy.2009.04.029

[20] Petersen, S.; Svendsen, S. 2012. Method for component-based economical optimisation for use in design of new low-energy buildings, Renewable Energy 38(1): 173-180. http://dx.doi.org/10.1016/j.renene.2011.07.019

[21] Užšilaitytè, L.; Martinaitis, V. 2010. Impact of the building renovation perodicity on its life cycle energy consumption, Energetika (2): 146-153.

[22] Oliveira, C.; Antunes, C. H. 2004. A multiple objective model to deal with economy-energy-environment interactions, European Journal of Operational Research 153(2): 370-385. http://dx.doi.org/10.1016/S0377-2217(03)00159-0

[23] Blom, I.; Itard, L.; Meijer, A. 2010. LCA-based environmental assessment of the use and maintenance of heating and ventilation systems in Dutch dwellings, Building and Environment 45(11): 2362-2372. http://dx.doi.org/10.1016/j.buildenv.2010.04.012

[24] Dylewski, R.; Adamczyk, J. 2011. Economic and environmental benefits of thermal insulation of building external walls, Building and Environment 46(12): 2615-2623. http://dx.doi.org/10.1016/j.buildenv.2011.06.023

[25] Verbeeck, G.; Hens, H. 2010. Life cycle inventory of buildings: A calculation method, Building and Environment 45(4): 1037-1041. http://dx.doi.org/10.1016/j.buildenv.2009.10.012

[26] Chantrelle, F. P.; Lahmidi, H.; Keilholz, W.; Mankibi, M. El.; Michel, P. 2011. Development of a multicriteria tool for optimizing the renovation of buildings, Applied Energy 88(4): 1386-1394. http://dx.doi.org/10.1016/j.apenergy.2010.10.002

[27] Juan, Y.-K.; Gao, P.; Wang, J. 2010. A hybrid decision support system for sustainable office building renovation and energy performance improvement, Energy and Buildings 42(3): 290-297. http://dx.doi.org/10.1016/j.enbuild.2009.09.006

[28] Risholt, C. B.; Time, B.; Hestnes, A. G. 2013. Sustainability assessment of nearly zero energy renovation of dwellings -based on energy, economy and home quality indicators, Energy and Buildings 60(2010). 
[29] Yu, Z.; Haghighat, F.; Fung, B. C. M.; Yoshino, H. 2010. A decision tree method for building energy demand modeling, Energy and Buildings 42(10): 1637-1646. http://dx.doi.org/10.1016/j.enbuild.2010.04.006

[30] Shin, Y.; Kim, T.; Cho, H.; Kang, K.-I. 2012. A formwork method selection model based on boosted decision trees in tall building construction, Automation in Construction 23: 47-54. http://dx.doi.org/10.1016/j.autcon.2011.12.007

[31] Sjögren, J.-U.; Andersson, S.; Olofsson, T. 2009. Sensitivity of the total heat loss coefficient determined by the energy signature approach to different time periods and gained energy, Energy and Buildings 41(7): 801-808. http://dx.doi.org/10.1016/j.enbuild.2009.03.001

[32] Fleiter, T.; Worrell, E.; Eichhammer, W. 2011. Barriers to energy efficiency in industrial bottom-up energy demand models-A review, Renewable and Sustainable Energy Reviews 15(6): 3099-3111. http://dx.doi.org/10.1016/j.rser.2011.03.025

[33] Martinaitis, V.; Kazakevičius, E.; Vitkauskas, A. 2007. A two-factor method for appraising building renovation and energy efficiency improvement projects, Energy Policy 35(1): 192-201. http://dx.doi.org/10.1016/j.enpol.2005.11.003

[34] Kaklauskas A., Zavadskas E. K., and Raslanas S., 2005, "Multivariant design and multiple criteria analysis of building refurbishments," Energy and Buildings, 37(4):. 361-372. http://dx.doi.org/10.1016/j.enbuild.2004.07.005

[35] Martinaitis, V.; Mikučionienè, R. 2013. Criteria for evaluation of energy efficiency measures in the management of building energetic characteristics, in CYSENI 2013. 10th international conference of young scientist on energy issues, Kaunas: 285-293. 